\title{
KETERAMPILAN DOSEN MODEL MATEMATIKA DAN HASIL BELAJAR MAHASISWA DALAM PRAKTIK LESSON STUDY
}

\author{
Zul Jalali Wal Ikram1), Najmawati Azis') \\ 1)SMA Islam Athirah 1 Makassar, Jl. Kajaolalido No. 22, Makassar; zuljalalialikram40@gmail.com \\ 2)Alumni Universitas Negeri Makassar, Jl. Daeng. Tata, Makassar; najmawatiazis95@gmail.com
}

\begin{abstract}
Abstrak. Tujuan penelitian ini adalah mendeskripsikan keterampilan dosen model matematika dan hasil belajar mahasiswa dalam praktik lesson study. Kegiatan lesson study memiliki tiga tahapan, yakni perencanaan (plan), praktik pembelajaran $(d o)$, dan observasi dan refleksi (see). Kegiatan refleksi sangat penting dalam aktivitas lesson study, karena sangat menentukan langkah perbaikan berikutnya. Kegiatan refleksi membutuhkan keterampilan mengajar dari dosen model. Pengumpulan data dilakukan bersamaan dengan kegiatan ongoing pada Kajian Praktek Lapangan (KPL) yang melibatkan 3 dosen model matematika dan 36 mahasiswa angkatan 2017 offering C Pendidikan Matematika, Universitas Negeri Malang. Hasil penelitian menunjukkan bahwa (1) keterampilan mengajar dosen model berkembang seiring dengan praktik lesson study, (2) praktik lesson study membantu dosen model dalam mengembangkan pembelajaran dan meningkatkan hasil belajar mahasiswa.
\end{abstract}

Kata Kunci. keterampilan, hasil belajar, lesson study

\section{The Skill of Mathematics Model Lecturer and Undergraduate Student Learning Ahievement in Lesson Study Practices}

\begin{abstract}
This research aims to describe the skill of mathematics model lecturer and the learning achievement of undergraduate students in lesson study practice. Lesson study activities consist of three phases, namely, planning (plan), teaching and learning practice (do), and observation and reflection (see). Reflection is a crucial phase in Lesson Study activity, since it determines the next step needed for improvement. Reflection activities require teaching skills of the model lecturers. The data was collected in line with the ongoing activities in the Field Work Practices involving 3 mathematics model lecturers and 36 undergraduate students, academic year of 2017 offering C Mathematics Education, Universitas Negeri Malang (Malang State University). The research result shows that (1) The model lecturer teaching skills develops along with lesson study practice; (2) lesson study practice supports model lecturers in developing teaching and learning, as well as improving students' learning achivements.
\end{abstract}

Keyword. skill, achevements, lesson study

\section{Pendahuluan}

Salah satu komponen utama untuk mempercepat peningkatan kualitas pendidikan di Indonesia adalah dengan meningkatkan kualitas dosen model atau dosen praktikan. Dosen model nantinya secara langsung berinteraksi dengan mahasisiswa dalam proses 
pembelajaran, sehingga pengaruhnya terhadap perkembangan mahasiswa dalam aspek kognitif, afektif, dan psikomotorik sangat besar. Begitupula dosen model sangat menentukan dalam membentuk pola pikir mahasiswa dalam proses belajar, membentuk karakter mahasiswa dalam bertindak, dan menginspirasi mahasiswa dalam mengembangkan diri.

Betapa pentingnya peran dosen model dalam meningkatkan kualitas pendidikan, maka peningkatan kualitas dosen model harus senantiasa dilakukan secara berkesinambungan. Salah satu program peningkatan kualitas dosen model adalah Kajian Praktek Lapangan (KPL) yang memiliki komponen pengembangan, yakni pembelajaran bermakna dan lesson study. Menurut Subanji (2013), pembelajaran bermakna merupakan suatu proses sistematis dan terencana yang dirancang oleh dosen untuk membelajarkan mahasiswa sehingga terjadi konstruksi pengetahuan melalui pengaitan pengetahuan baru dengan pengetahuan lama dan mahasiswa mampu memahami materi lebih dari sekedar tahu; menjawab apa, mengapa, dan bagaimana; menginternalisasi pengetahuan ke dalam diri sedemikian hingga membentuk perilaku; dan mengolah perilaku menjadi karakter diri.

Untuk mempercepat perwujudan pembelajaran bermakna, dosen model perlu difasilitasi untuk berkolaborasi dalam merencanakan (plan), melaksanakan (do), dan merefleksikan (see) pembelajaran yang dikenal dengan lesson study. Hal penting dan menarik untuk dikaji dalam pelaksanaan lesson study adalah proses refleksi pembelajaran. Proses refleksi sangat menentukan perbaikan pembelajaran selanjutnya.

Semakin detail dalam proses refleksi, maka memiliki peluang lebih besar untuk memperoleh masukan dalam merancang perbaikan pembelajaran berikutnya. Sebaliknya proses refleksi "yang hanya sekadarnya", tidak akan mampu berdampak pada proses perbaikan pembelajaran. Agar bisa melakukan proses refleksi yang berkualitas, perlu memiliki keterampilan yang lebih baik.

Kajian terkait dengan keterampilan dosen model dalam mengajar sudah banyak dilakukan (Gurol, 2011; Choy \& Cheah, 2009; Rudd, 2007). Gurol (2011) menyatakan bahwa keterampilan berfikir reflektif dalam mengajar merupakan proses kegiatan terarah dan tepat dimana seseorang menyadari untuk dapat menganalisis, mengevaluasi, memotivasi, dan mendapatkan makna yang mendalam. Dalam kegiatan refleksi pembelajaran di lesson study, dosen model dituntut untuk menganalisis dan mengevaluasi proses pembelajaran yang sudah dilakukan sekaligus mengambil makna "positif" nya supaya bisa dijadikan bahan perbaikan bersama antar dosen model. Pada akhirnya proses refleksi dapat memotivasi dosen model dalam melaksanakan pembelajaran yang bermakna dan memecahkan masalah yang terjadi dalam pembelajaran. Hal ini sesuai dengan pendapat Sezer (dalam Chee \& Pao, 2012) yang menyatakan bahwa keterampilan dalam mengajar sebagai suatu kesadaran tentang informasi yang dibutuhkan untuk menyelesaikan masalah.

Choy \& Cheah (2009) dan Rudd (2007) menekankan bahwa keterampilan dalam mengajar dapat berkembangkan secara maksimal jika prosesnya dikaitkan dengan 
kegiatan sehari-hari. Dalam kegiatan lesson study di KPL, proses refleksi dilakukan berdasarkan kenyataan pembelajaran yang dialami, diamati, dan dirasakan secara langsung dari suatu praktik pembelajaran. Karena itu keterampilan dalam mengajar tidak hanya didasarkan pada teori tetapi lebih menekankan pada fakta yang ditemui sebagai suatu masalah atau suatu "pelajaran berharga" dalam praktik pembelajaran. Keterampilan mengajar dilakukan secara terus menerus dalam praktik lesson study, dengan demikian keterampilan dalam mengajar tersebut dapat mengasah kemampuan dari peserta lesson study.

Selain keterampilan, hasil belajar pula sangat penting, karena hal tersebut merupakan salah satu tolak ukur dari keberhasilan suatu metode yang digunakan dalam proses pembelajaran. Hasil belajar merupakan bagian terpenting dalam pembelajaran. Nana Sudjana (2009) mendefinisikan hasil belajar mahasiswa pada hakikatnya adalah perubahan tingkah laku sebagai hasil belajar dalam pengertian yang lebih luas mencakup bidang kognitif, afektif, dan psikomotorik. Dimyati dan Mudjiono (2006) juga menyebutkan hasil belajar merupakan hasil dari suatu interaksi tindak belajar dan tindak mengajar. Dari sisi dosen, tindak mengajar diakhiri dengan proses evaluasi hasil belajar. Dari sisi siswa, hasil belajar merupakan berakhirnya pengajaran dari puncak proses belajar. Jenis data berupa hasil belajar selanjutnya dikategorikan secara kualitatif berdasarkan teknik kategorisasi menurut methods of grading in Summative Evaluation dari Bloom, Madaus \& Hastings (Gerson, 2003: 19) adalah:

Tabel 1. Kategori Hasil Belajar

\begin{tabular}{|c|c|}
\hline Nilai hasil belajar & Kategori \\
\hline $90 \leq \mathrm{x}$ & Sangat tinggi \\
\hline $75 \leq \mathrm{x}<90$ & Tinggi \\
\hline $60 \leq \mathrm{x}<75$ & Sedang \\
\hline $40 \leq \mathrm{x}<60$ & Rendah \\
\hline $\mathrm{x}<40$ & Sangat Rendah \\
\hline
\end{tabular}

Untuk itu, dalam penelitian ini peneliti tertarik melihat bagaimana keterampilan dosen model dan hasil belajar mahasiswa dalam praktik lesson study.

\section{Metode Penelitian}

Penelitian ini dilakukan dalam kegiatan real teaching Kajian Praket Lapangan (KPL). Peneliti berpartisipasi langsung dalam proses pembelajaran di kelas sebagai dosen model bersama dua dosen model lainnya. Metode pengambilan data yang dilakukan adalah observasi partisipatif. Subjek penelitian ini adalah 3 dosen model yang sedang mengikuti KPL dan 36 mahasiswa S1 angkatan 2017 program studi pendidikan matematika Universitas Negeri Malang. Data yang diperoleh dari 3 dosen model adalah berupa rekaman hasil refleksi dan data yang diperoleh dari 36 mahasiswa adalah berupah hasil belajar. Selanjutnya data dianalisis dan dipaparkan secara kualitatif. 


\section{Hasil Penelitian dan Pembahasan}

Keterampilan dosen model matematika dan hasil belajar mahasiswa dalam praktik lesson study akan dipaparkan berdasarkan kegiatan lesson study yang memiliki tiga tahapan, yakni perencanaan (plan), praktik pembelajaran (do), dan observasi dan refleksi (see).

\subsection{Deskripsi Tahap Perencanaan (Plan)}

Tujuan dilaksanakn plan ini adalah agar dosen model dapat melakukan do dengan baik saat di kelas. Pada tahap plan, terdapat dua kegiatan yang dilakukan, yaitu: (1) menyusun perangkat bersama kelompok KPL; (2) diskusi perangkat yang telah disusun bersama dosen pembimbing. Penyusunan RPP berdasarkan materi yang telah ditentukan. RPP disusun dengan empat kolom sesuai dengan arahan yang diberikan oleh koordinator pascasarjana pendidikan matematika. Metode pembelajaran yang digunakan adalah ceramah sesuai dengan arahan dosen pembimbing. Pada saat penyusunan RPP, anggota kelompok saling bertukar ide untuk menyusun kegiatankegiatan pembelajaran, sehingga kegiatan sesuai dengan materi yang akan disampaikan. Setelah penyusunan RPP kegiatan selanjutnya adalah konsultasi dengan dosen pembimbing. Tujuannya adalah agar tidak terjadi kesalahan konsep saat melaksanakan do. Selain itu dari kegiatan konsultasi ini, praktikan meminta masukan dari dosen pembimbing, agar praktikan lebih siap dalam melaksanakan $d o$.

Berdasarkan dari uraian di atas dapat kita simpulkan bahwa tahap plan berjalan dengan lancar. Semua dosen praktikan yang berada dalam kelompok memberikan kontribusi yang sama besar dalam penyusunan perangkat perkuliahaaan. Selain itu, dosen pembimbing juga memberikan arahan yang mudah dilakukan oleh dosen model yaitu memperbaiki tujuan pembelajaran yang terdapat pada RPP.

\subsection{Deskripsi Tahap Pembelajaran (Do)}

Berdasarkan pelaksanaan dalam tahapan do, dapat disimpulkan bahwa secara keseluruhan do berjalan dengan lancar. Kesesuaian kegiatan yang dilakukan dosen model saat do juga mencapai $90 \%$ dengan RPP yang telah dibuat. Walaupun masih terdapat beberapa langkah kegiatan RPP yang tidak terlaksana. Ketidakterlaksanaan beberapa langkah RPP tersebut dikarenakan alokasi waktu yang terlalu singkat dan membutuhkan waktu lama pada diskusi kelompok. Oleh karena itu mungkin untuk lesson study selanjutnya bisa membutuhkan persiapan yang lebih baik terlebih dahulu sebelum melakukan pembelajaran langsung di kelas sesungguhnya.

Penggunanaan metode ceramah, diskusi dan tanya jawab yang digunakan pada penyusunan RPP dinilai tepat untuk kelas C program studi Pendidikan Matematika ini. Mahasiswa di kelas ini tidak merasa segan untuk bertanya, membenarkan, dan bahkan menyanggah. Diskusi dapat berjalan dengan aktif, efektif dan tetap menyenangkan selama waktu pelajaran berlangsung. Bahkan saat pembahasan latihan soal pun 
mereka masih tetap semangat untuk membahas seluruhnya meskipun waktu perkuliahan sudah habis bahkan mengalami keterlambatan.

Saat tahap do masih terdapat juga beberapa masalah saat proses pembelajaran, berikut masalah-masalah yang ditemukan. (1) Keaktifan mahasiswa yang duduk di pojok sebelah kiri masih kurang. Hal ini diakibatkan karena mahasiswa tersebut hanya memilih diam disaat tidak memahami materi daripada harus menanyakannya. Padahal dosen model telah memintanya untuk bertanya agar kita bisa sama-sama belajar. (2) Terdapat mahasiswa yang belum memahami materi dengan baik sehingga ketika siswa di tunjuk mengerjakan soal yang diberikan di papan tulis, mahasiswa tersebut masih ragu dan tidak berani dalam menuliskan sehingga dosen model memberikan arahan agar siswa mengingat konsep materi yang digunakan dalam menyelesaikan soal tersebut. (3) Alokasi waktu yang digunakan terkadang kurang karena keterbatasan waktu yang diberikan untuk tiap dosen praktikan dalam menyampaikan materi. Sehingga mahasiswa harus dengan cepat menangkap materi yang disampaikan.

\subsection{Deskripsi Tahap Refleksi (See)}

Setelah tahap do selesai dilaksanakan, dilanjutkan dengan tahap refleksi. Refleksi ini dilakukan terhadap pembelajaran yang baru saja dilaksanakan di kelas. Refleksi ini membahas tentang segala sesuatu yang terjadi selama proses pembelajaran yang baru saja dilakukan, baik hal positif ataupun negatifnya. Pembahasan yang dilakukan juga berkaitan dengan apa saja yang perlu dilakukan untuk mengatasi segala kekurangan yang terjadi serta apa saja kelebihan yang perlu dipertahankan untuk pembelajaran selanjutnya.

Kegiatan refleksi berjalan lancar dan sesuai harapan. Seluruh dosen praktikan hadir dan melaporkan hasil observasinya. Karena kegiatan refleksi (see) dilaksanakan sesaat setelah kegiatan perkuliahan $(d o)$, maka kegiatan refleksi dilakukan dengan maksimal. Masing-masing pihak yang terlibat seperti dosen model, dosen pembimbing dan observer masih ingat dengan benar setiap detail kejadian pada saat pelaksanaan.

Masing-masing observer melaporkan hasil observasi terhadap mahasiswa yang diamati secara detail. Kegiatan apapun yang dilakukan mahasiswa selama proses pembelajaran dilaporkan. Beberapa kegiatan tersebut adalah (1) bagaimana keaktifan mahasiswa dalam mengikuti perkuliahaan, (2) bagaimana mahasiswa saat berdiskusi dengan temannya, apakah menerima saja atau memberikan ide, (3) kesalahan-kesalahan mahasiswa dalam mengkonstruk pemahaman terhadap materi yang diajarkan, dan (4) kegiatan lain mehasiswa saat proses pembelajaran. Namun, tidak hanya menyebutkan secara umum masalah-masalah yang terjadi saat proses pembelajaran tapi juga disertai bukti (dengan menyebutkan nama/nomor dari mahasiswa yang melakukan kegiatan tersebut) dan analisis mengapa mahasiswa melakukan kegiatan tersebut.

Berikut beberapa analisis yang disampaikan oleh para observer terkait masalah yang muncul. (1) Beberapa mahasiswa kurang aktif sehingga perlu diberikan pancingan atau reward untuk menarik perhatian mahasiswa agar lebih aktif. (2) Beberapa mahasiswa 
masih kurang berani dalam menuliskan jawaban yang diperolehnya sehingga ketika dosen model menunjuk mereka, mahasiswa tersebut meyakinkan jawabannya terlebih dahulu kepada temannya. (3) Beberapa mahasiswa juga lebih memilih bertanya secara individual kepada guru dibandingkan harus memperdengarkan pertanyaannya kepada mahasiswa lain. (4) Beberapa mahasiswa saat berdiskusi kelompok lebih memilih sibuk dengan kegiatan lainnya dari pada ikut berkontribusi dalam menyelesaikan soalsoal yang diberikan.

Setelah laporan dari masing-masing observer, berikutnya adalah komentar dari dosen pembimbing. Karena komentar tentang mahasiswa telah lengkap disampaikan oleh observer maka komentar dosen pembimbing hanya berfokus pada performa dosen model. Komentar yang disampaikan oleh dosen pembimbing terhadap dosen model yaitu dosen model harus lebih teliti memperhatikan mahasiswa saat proses pembelajaran dan kemungkinan mahasiswa yang kurang aktif tersebut bukan karena kesalahan dosennya tapi karena kesadaran mahasiswanya sendiri. Meskipun demikian terdapat beberapa saran yang disampaikan oleh dosen pembimbing. Saran-saran dari dosen pembimbing dijadikan bahan perbaikan untuk lesson study yang akan dilakukan ketika menjadi pendidik nantinya.

\subsection{Hasil Belajar}

Dalam penerapan lesson study hasil belajar yang diperoleh setelah diolah adalah sebagai berikut:

Tabel 2. Hasil Belajar dengan Praktik Lesson Study

\begin{tabular}{|c|c|c|c|}
\hline \multicolumn{3}{|c|}{ KOMPONEN NILAI } & Nilai Akhir \\
\hline \multicolumn{3}{|c|}{ Bobot Skor $(0-100)$} & \multirow{2}{*}{100} \\
\hline No & NIM & NAMA & \\
\hline 1 & 150312603060 & Afifah Rachmawati & 44.4 \\
\hline 2 & 170311611519 & Aldona Vivi Anggita & 82.85 \\
\hline 3 & 170311611624 & Alifya Nanda Nurdianna & 78.25 \\
\hline 4 & 170311611663 & Anggie Hanidar Aziza & 81.7 \\
\hline 5 & 170311611562 & Anis Magfiroh & 91.5 \\
\hline 6 & 170311611629 & Annisa Hanim & 68.6 \\
\hline 7 & 170311611657 & Arum Kusuma Rini & 83.2 \\
\hline 8 & 170432622542 & $\begin{array}{lll}\text { Azizah Nur } & \text { Laily } \\
\text { Rahmawati } & & \end{array}$ & 71.8 \\
\hline 9 & 170311611625 & B.Yuyun Dwi Asrika & 60.2 \\
\hline 10 & 170311611565 & Bilqis Syarifa Chusna & 97.7 \\
\hline 11 & 170311611626 & $\begin{array}{l}\text { Crysnadia Anggareta } \\
\text { Bestari }\end{array}$ & 81.8 \\
\hline 12 & 170311611560 & Devi Nurfitriyani & 74.6 \\
\hline 13 & 170311611518 & Eka Viola Yunita & 92.75 \\
\hline 14 & 170311611522 & Farah Dibah & 64.75 \\
\hline 15 & 170311611566 & Heru Eko Ali Anto & 91.35 \\
\hline
\end{tabular}




\begin{tabular}{|c|c|c|c|}
\hline \multicolumn{3}{|c|}{ KOMPONEN NILAI } & Nilai Akhir \\
\hline \multicolumn{3}{|c|}{ Bobot Skor $(0-100)$} & \multirow{2}{*}{100} \\
\hline No & NIM & NAMA & \\
\hline 16 & 170311611661 & Imira Ula Chomsa Adistya & 73.55 \\
\hline 17 & 170311611558 & Kathrine Ayu Maghfirah & 57 \\
\hline 18 & 170311611521 & Lailiyatul Umroh & 55.85 \\
\hline 19 & 170311611592 & Layla Ramadhan Nafi`A & 85.55 \\
\hline 20 & 170311611658 & Lorenza Tri Handayani & 86 \\
\hline 21 & 170311611559 & M. Haris Alfarizi & 84.1 \\
\hline 22 & 170311611664 & Muhamad Farid Assegaff & 63.35 \\
\hline 23 & 170311611659 & Muhammad N. Maulidani & 76.35 \\
\hline 24 & 170311611523 & Nabila Ekaputri Widuri & 88.1 \\
\hline 25 & 170311611628 & Nanda Azzahra Putri & 64.6 \\
\hline 26 & 170311611595 & Nizi Hajar & 96 \\
\hline 27 & 170311611630 & Puput Ayu Rahmawati & 59.75 \\
\hline 28 & 170311611623 & Rahmadyah Nur Toyibah & 66.85 \\
\hline 29 & 170311611517 & Ratna Nagayomi & 77.95 \\
\hline 30 & 170311611564 & Rianti Hidaiyah & 92 \\
\hline 31 & 170311611596 & Risna Nuraini & 97.55 \\
\hline 32 & 170311611665 & Salsa Anisa Nur Azizah & 78.8 \\
\hline 33 & 170311611662 & Urbach Aisa Kemal & 85.45 \\
\hline 34 & 170311611660 & Yolawati Arifin & 75.75 \\
\hline 35 & 170311611666 & Yuliana D Randongkir & 59.2 \\
\hline 36 & 170311611598 & Yusril Rizqi Putra Abdillah & 0 \\
\hline
\end{tabular}

Dari tabel di atas terlihat bahwa ada 7 mahasiswa yang berada pada kategori sangat tinggi, 14 mahasiswa yang berada pada kategori tinggi, 9 mahasiswa yang berada pada kategori sedang, 5 mahasiswa yang berada pada kategori rendah, dan 1 mahasiswa yang berada pada kategori sangat rendah. Dari hasil tersebut dapat disimpulkan bahwa dengan praktik lesson study yang digunakan dalam kelas tersebut hasil belajar meningkat karena 30 mahasiswa dari 36 mahasiswa berhasil mendapatkan skor berada dalam kategori sedang hingga kategori sangat tinggi.

\section{Kesimpulan}

Keterampilan dosen model berkembang seiring praktik lesson study mulai dari aktifitas perencanaan pembelajaran, praktik pembelajaran, dan refleksi pembelajaran. Keterampilan dosen model dapat membantu dalam mengembangkan pembelajaran bermakna, kreatif, dan menyenangkan melalui proses refleksi pasca praktik pembelajaran. Kegiatan refleksi secara kolaboratif dapat meningkatkan keterampilan dosen model dalam mengajar. Hal ini terjadi karena dosen model saling belajar dan saling membantu untuk berinovasi dalam mengembangkan pembelajaran. Hasil belajar 
pada mahasiswa meningkat karena 30 mahasiswa dari 36 mahasiswa berhasil mendapatkan skor berada dalam kategori sedang hingga kategori sangat tinggi.

\section{Daftar Pustaka}

Choy \& Cheah, 2009. Teacher Percep-tions of Critical Thinking Among Students and its Influence on Higher Education. International Journal of Teaching and Learning in Higher Education, 20(2), 196-2.

Dimyati dan Mudjiono (2006). Belajar dan Pembelajaran. Jakarta: PT. Rineka Cipta.

Gerson. 2003. Evaluasi Hasil Belajar yang relevan dengan kurikulum berbasis kompetensi. Surabaya: Yayasan Pengkajian Pengembangan Pendidikan Indonesia Timur (YP3IT).

Gurol. A. 2011. Determining the reflective thinking skills of pre-service tea-chers in learning and teaching pro-cess. Energy Education Science and Technology Part B: Social and Educational Studies 2011 Volume (issue) 3(3): 387-402.

Nana Sudjana. 2009. Penilaian Hasil Proses Belajar Mengajar. Bandung: PT Remaja Rosdakarya.

Rudd, R. D. 2007. Defining Critical Thinking. Techniques, 82(7), 46-49.

Subanji, 2013. Revitalisasi Pembelajaran Bermakna dan Penerapannya dalam Pembelajaran Matematika Sekolah. Makalah disajikan di Seminar Nasional TEQIP 9 November 2013 di Universitas Negeri Malang. 